\title{
Spherical Agglomeration of Naproxan by Solvent Change Method
}

\author{
Parthasarathi Keshavarao Kulkarni, Mudit Dixit*, Achin Jain \\ Department of Pharmaceutics, J.S.S College of Pharmacy, S.S Nagar, Mysore-570015, India.
}

Original Research Article

\begin{abstract}
Naproxen, an anti-inflammatory drug, exhibits poor water solubility and flow properties. Spherical agglomerates were prepared by solvent change method. Solvent composition for spherical agglomeration was determined by constructing ternary diagram. Crystallization medium used for spherical agglomerates of naproxen consisted of tetra-hydro-furan (good solvent); water (poor solvent); isopropyl acetate (bridging liquid) in the ratio of 29:61:10, respectively. Spherical agglomerates were characterized by differential scanning calorimetry, infrared spectroscopy, X-ray diffractometry and scanning electron microscopy. Micromeritic and dissolution behavior studies were carried out. Process variables such as amount of bridging liquid, stirring time and duration of stirring were optimized. Dissolution profile of the spherical agglomerates was compared with pure sample and recrystallized sample. Spherical agglomerates exhibited decreased crystallinity and improved micromeritic properties. The dissolution of the spherical agglomerates was not improved compared with pure sample because the dissolution of naproxen dependent on particle size or surface area.
\end{abstract}

Key words: Spherical agglomerates, Naproxen, Crystallinity, Dissolution.

\section{INTRODUCTION}

Formulation and manufacture of solid oral dosage forms, and tablets in particular, have undergone rapid change and development over the last several decades. One of the most revolutionary technologies is that of direct compression (Chourasia et al., 2004, Kulkarni et al., 2002). Direct compression is economical, facilitates processing without the need of moisture, heat and involves small number of processing steps. In direct tabletting method, it is necessary to increase flowability and compressibility of the bulk powder in order to retain a steady supply of powder mixture to the tabletting machine and sufficient mechanical strength of the compacted tablets. In addition to increasing efficiency of the manufacturing

\footnotetext{
*Corresponding Author

Mudit Dixit

Department of Pharmaceutics

J.S.S College of Pharmacy

S.S Nagar, Mysore-570015, India.

Contact No.: +919035508450

E-mail: muditdixit911@yahoo.com
}

process it is also important to increase bioavailability of the drug by improving the solubility of the bulk drug powder. Spherical agglomeration is one of such techniques to improve the micromeritic properties and dissolution of drug.

Spherical agglomeration process is a multiple unit process in which crystallization, agglomeration and spheronization can be carried out simultaneously in one step. The resultant crystals can be designated as spherical agglomerates (Martino et al., 1999, Sano et al., $1987 \& 1990)$. Due to the characteristic shape, the micromeritic properties such as flowability, pack-ability and compressibility of the resultant crystals are dramatically improved, so that direct tableting or coating is possible without further processing (e.g. mixing, agglomeration, sieving, etc.).

Spherical agglomeration is a process of formation of aggregates of crystals held together by liquid bridges. The agglomerates are formed 
by agitating the crystals in a liquid suspension in presence of binding agent. The binding liquid should be immiscible in the suspending medium but capable of cementing the particles to be agglomerated. The properties of the particles so designed vary greatly as compared to the fine crystalline material. These agglomerates were found to have good flow-ability and compressibility (Paradkar et al., 2002, Chourasia et al., 2004, Janos et al., 2004). This technique can also be exploited to increase solubility, dissolution and hence bioavailability of poorly soluble drugs (Takeo et al., 1990, Piera et al., 2000, Nocent et al., 2004, Yousef et al., 2005). These modifications allow for the practice of more efficient manufacturing methods that could save time and reduces economic risk. Naproxen exhibits poor flow, a high tendency of adhesion and shows poor dissolution properties (Mura et al., 1996, Gordon et al., 1990). Various methods were used to increase the flow properties of naproxen, e.g., spheronisation, direct compression, coating, granulation etc.

\section{MATERIALS AND METHODS}

Naproxan was obtained as a gift sample from Micro labs, Bangalore, India. Tetra-hydro-furan and isopropyl acetate were procured from Merck, Mumbai, India. All chemicals and buffers used were of analytical grade.

\section{Preparation of Naproxen spherical crystals}

Naproxen (5 gm) was dissolved in $29 \mathrm{ml}$ tetrahydro-furan heated at $45^{\circ} \mathrm{C}$. The drug solution was poured quickly in to $61 \mathrm{ml}$ of water maintained at $20^{\circ} \mathrm{C}$ under continuous stirring with paddle device, $500( \pm 5) \mathrm{rpm}$. When fine crystals of naproxen began to form, $10 \mathrm{ml}$ of isopropyl acetate was added. After 25 mins of stirring spherical crystals were formed and were separated from the solution by filtration. Spherical crystals were dried at $45^{\circ} \mathrm{C}$ for 12 hours.

\section{Recrystallization of Naproxen}

Changes in crystal lattice, being induced by solvents, can influence the physicochemical properties of the substance. Hence the mechanical, micromeritic and dissolution properties of miroparticles were compared with commercial sample and recrystallized sample. Recrystallization of naproxen was carried out using same solvent composition as used for spherical crystallization. Naproxen (5 gm) was dissolved in $29 \mathrm{ml}$ tetra-hydro-furan heated at $45^{\circ} \mathrm{C}$. The drug solution was poured quickly in to $61 \mathrm{ml}$ of water maintained at $20^{\circ} \mathrm{C}$. $10 \mathrm{ml}$ of isopropyl acetate was added. The crystals of naproxen were collected by filtration and were dried at $45^{\circ} \mathrm{C}$ for 12 hours.

\section{Drug content}

Spherical agglomerates $(50 \mathrm{mg})$ were triturated with $10 \mathrm{ml}$ of water. Allowed to stand for 10 mins with occasional swirling and methanol was added to produce $100 \mathrm{ml}$. after suitable dilution. Absorbance of the resulting solution was measured at $248.5 \mathrm{~nm}$. Drug content was determined from standard plot (Paradkar et al., 2002).

\section{Differential scanning calorimetry (DSC)}

A DSC study was carried out to detect possible polymorphic transition during the crystallization process. DSC measurements were performed on a DSC DuPont 9900, differential scanning calorimeter with a thermal analyzer.

\section{Fourier transform infrared (FTIR) spectroscopy}

The FTIR spectral measurements were taken at ambient temperature using a Shimadzu, Model 8033 (USA).

\section{X-ray analysis (XRD)}

X-Ray powder diffraction patterns were obtained at room temperature using a Philips $X^{\prime}$ Pert MPD diffractometer, with $\mathrm{Cu}$ as anode material and graphite monochromator, operated at a voltage of $40 \mathrm{~mA}, 45 \mathrm{kV}$.

\section{Scanning electron microscopy (SEM)}

Scanning electron microscopic (Joel- LV-5600, USA, with magnification of 250x) photographs were obtained to identify and confirm spherical nature and surface topography of the crystals.

\section{Micromeritic properties}

Particle size of recrystallized samples and pure samples were determined by microscopic method using calibrated ocular micrometer and size of spherical agglomerates was determined 
Table 1. Effect of variables on formulation of spherical agglomerates of Naproxen

\begin{tabular}{|c|c|c|}
\hline Parameter & Variable & Observation \\
\hline $\begin{array}{l}\text { Conc. of bridging } \\
\text { liquid } \\
\text { (Isopropyl acetate) }\end{array}$ & $\begin{array}{c}2 \% \\
8 \% \\
10 \%\end{array}$ & $\begin{array}{l}\text { No agglomeration } \\
\text { No agglomeration } \\
\text { Agglomeration }\end{array}$ \\
\hline Agitation speed & $\begin{array}{l}300 \pm 5 \\
400 \pm 5 \\
500 \pm 5 \\
600 \pm 5 \\
700 \pm 5\end{array}$ & $\begin{array}{l}\text { Clumps } \\
\text { Spherical \& large } \\
\text { Spherical } \\
\text { Spherical \& small } \\
\text { Irregular shape \& } \\
\text { small }\end{array}$ \\
\hline Agitation time & $\begin{array}{l}20 \mathrm{~min} \\
25 \mathrm{~min}\end{array}$ & $\begin{array}{l}\text { Incomplete } \\
\text { agglomerates } \\
\text { Spherical } \\
\text { agglomerates }\end{array}$ \\
\hline Temperature & $\begin{array}{l}20 \pm 1^{\circ} \mathrm{C} \\
30 \pm 1^{\circ} \mathrm{C} \\
45 \pm 1^{\circ} \mathrm{C}\end{array}$ & $\begin{array}{l}\text { Agglomeration } \\
\text { Loose Spherical } \\
\text { agglomerates } \\
\text { Very large } \\
\text { agglomerates }\end{array}$ \\
\hline $\begin{array}{l}\text { Mode of addition } \\
\text { of bridging liquid }\end{array}$ & $\begin{array}{l}\text { Whole at a } \\
\text { time } \\
\text { Drop wise }\end{array}$ & $\begin{array}{l}\text { Crystals of irregular } \\
\text { geometry } \\
\text { Spherical } \\
\text { agglomerates }\end{array}$ \\
\hline
\end{tabular}

by sieving method. Apparent particle densities of agglomerated and un-agglomerated crystals were measured using a Pycnometer. Carr's index was determined from powder volumes at the initial stage and after 1250 tappings to constant volume (Electolab, Mumbai). The angle of repose of agglomerated and commercial crystals was measured by fixed funnel method.

\section{Mechanical Properties}

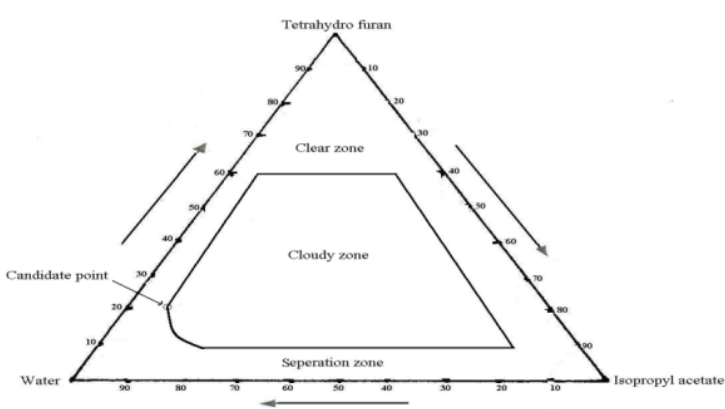

Figure 1. A Ternary diagram of tetra-hydro-furan, isopropyl acetate (binding solvent), and water (circle indicates suitable mixture zone for phase partition of Naproxen).
Tensile strength (Chourasia et al., 2004) of spherical agglomerates was determined by compressing $500 \mathrm{mg}$ of crystals using hydraulic press at different ton $/ \mathrm{cm}^{2}$ for $1 \mathrm{~min}$. The compacts stored in desiccator for overnight to allow elastic recovery. The thickness and diameter were measured for each compact. The hardness of each compact was then measured using Pfizer hardness tester. The tensile strength $(\sigma)$ of the compact (ton/ $/ \mathrm{cm}^{2}$ ) was calculated using following equation.

$$
\sigma=2 \mathrm{~F} / \pi \mathrm{Dt}
$$

Where, $\mathrm{F}, \mathrm{D}$ and $\mathrm{t}$ are hardness (ton), compact diameter $(\mathrm{cm})$ and thickness $(\mathrm{cm})$, respectively.

\section{Crushing strength}

Crushing strength (Chourasia et al., 2004) of agglomerates was determined by using mercury lad cell method. It was carried out using $10 \mathrm{ml}$ glass hypodermic syringe. Tip of syringe and top end of the plunger are removed. The barrel was used as hollow support and guide tube with close fitting to the plunger. A window was cut at the lower end of the barrel to facilitate placement of the agglomerate on the base of platen. The plunger acted as movable platen. It was set directly on the agglomerates, positioned on the lower platen. Mercury is added to the plunger at a predetermined rate from burette from a fixed height. The total weight of mercury plus weight of plunger required to break the agglomerates was the crushing strength.

\section{Solubility studies}

The solubility (Yousef et al., 2005) of Naproxen spherical agglomerates in water was determined by taking excess quantity of spherical agglomerates in $50 \mathrm{ml}$ to screw- capped glass

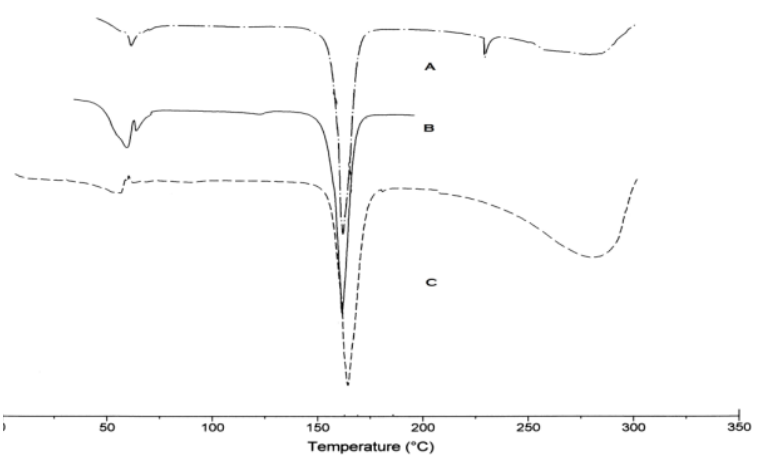

Figure 2. DSC curves of different crystals of Naproxen: A) Commercial sample B) Re crystallized Naproxen, C) spherical agglomerates of Naproxen. 
Table 2. Micromeritic properties of naproxen commercial sample, recrystallized naproxen and spherical agglomerates

\begin{tabular}{lccc}
\hline Properties & Commercial sample & $\begin{array}{c}\text { Re-crystallized } \\
\text { Sample }\end{array}$ & $\begin{array}{c}\text { Spherical crystals by solvent } \\
\text { change method }\end{array}$ \\
\hline Mean Particle size. $\mu \mathrm{m}$ & $<3$ & $15 \pm 3.2$ & $832.2 \pm 10.3$ \\
Angle of repose & $32.88 \pm 1.2$ & $33.8 \pm 1.32$ & $26 \pm 0.52$ \\
Friability $(\%)$ & -- & -- & $1 \pm 0.51$ \\
Bulk density $(\mathrm{gm} / \mathrm{ml})$ & $0.2873 \pm 0.09$ & $0.2523 \pm 0.085$ & $0.2886 \pm 0.06$ \\
Tapped density(gm/ml) & $0.5167 \pm 0.08$ & $0.3610 \pm 0.078$ & $0.2951 \pm 0.068$ \\
Carr's index (\%) & $44.38 \pm 0.02$ & $30.1 \pm 0.013$ & $20.2 \pm 0.02$ \\
Hausner's ratio & $0.556 \pm 0.03$ & $0.699 \pm 0.01$ & $0.9779 \pm 0.02$ \\
Tensile strength $(\mathrm{Kg})$ & $1.2 \pm 0.12$ & $1.6 \pm 0.18$ & $3.0 \pm 0.23$ \\
Crushing strength. gm & -- & -- & $157.09 \pm 1.28$
\end{tabular}

vials filled with water. The vials were shaken for twenty four hours on mechanical shaker. The solution was filtered through Whatmann filter paper No.1 and the drug concentration was determined spectrophotometrically at $258.5 \mathrm{~nm}$.

\section{Dissolution studies of agglomerates}

The dissolution (Paradkar et al., 2002) of Naproxen pure sample, spherical agglomerates and recrystallized sample was determined by using USP dissolution apparatus XXIV-Type II (Electro Lab, Mumbai). Dissolution medium was $900 \mathrm{ml} 7.4$ phosphate buffer. The amount of dissolved drug was determined using UV spectrophotometric method (UV 1601 A Shimadzu, Japan) at $258.5 \mathrm{~nm}$.

\section{RESULT AND DISCUSSION}

Tetra-hydro-furan is miscible in any proportion with water and isopropyl acetate. If the ternary diagram is envisaged, to select the solvent composition, isopropyl acetate and water are like an emulsion in a large area of the Ternary

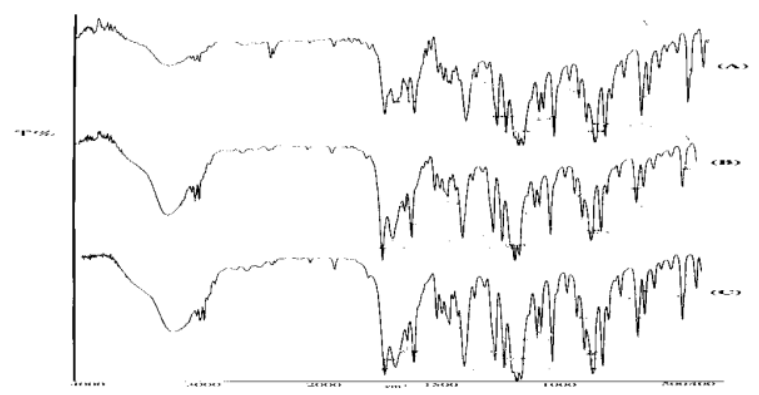

Figure 3. IR spectra of naproxen A) Naproxen B) Recrystallized naproxen C) Spherical agglomerates of naproxen diagram (Fig. 1).

The \% Yield obtained was found in the range of $85-92 \%$ with drug content in the range of 98 $99 \%$. Other process parameters like amount and mode of addition of bridging liquid, stirring speed and time and temperature were considered for optimization (Table 1).

The DSC thermogram (Fig. 2) shows a sharp endothermic peak for all the naproxen crystals. This one step melt might be due to only one crystal form (Triclinic) of the naproxen formed during the crystallization process, thus indicating that naproxen did not undergo any crystal modification.

Infrared spectra of naproxen, recrystallized naproxen and spherical crystals showed characteristic principal peaks at wave numbers $1724 \mathrm{~cm}^{-1}(\mathrm{C}=\mathrm{O}$ stretching vibrations of $-\mathrm{COOH}$

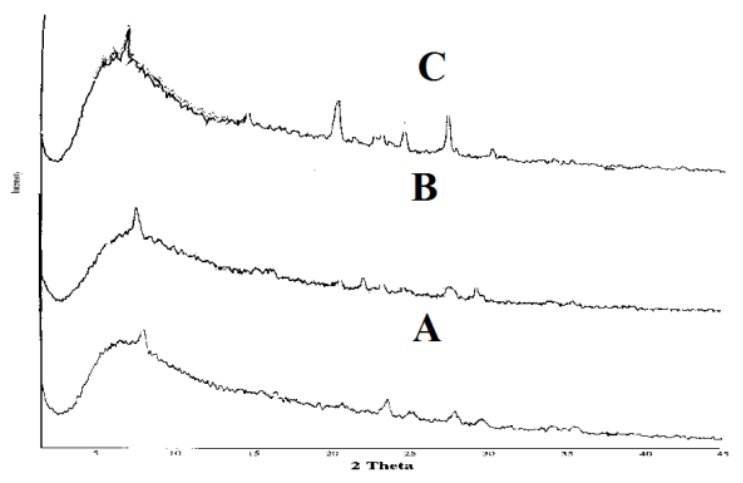

Figure 4. Different cell parameters obtained for naproxen crystals from XRD data. A) Naproxen B) Recrystallized naproxen C) Spherical agglomerates of naproxen 
A
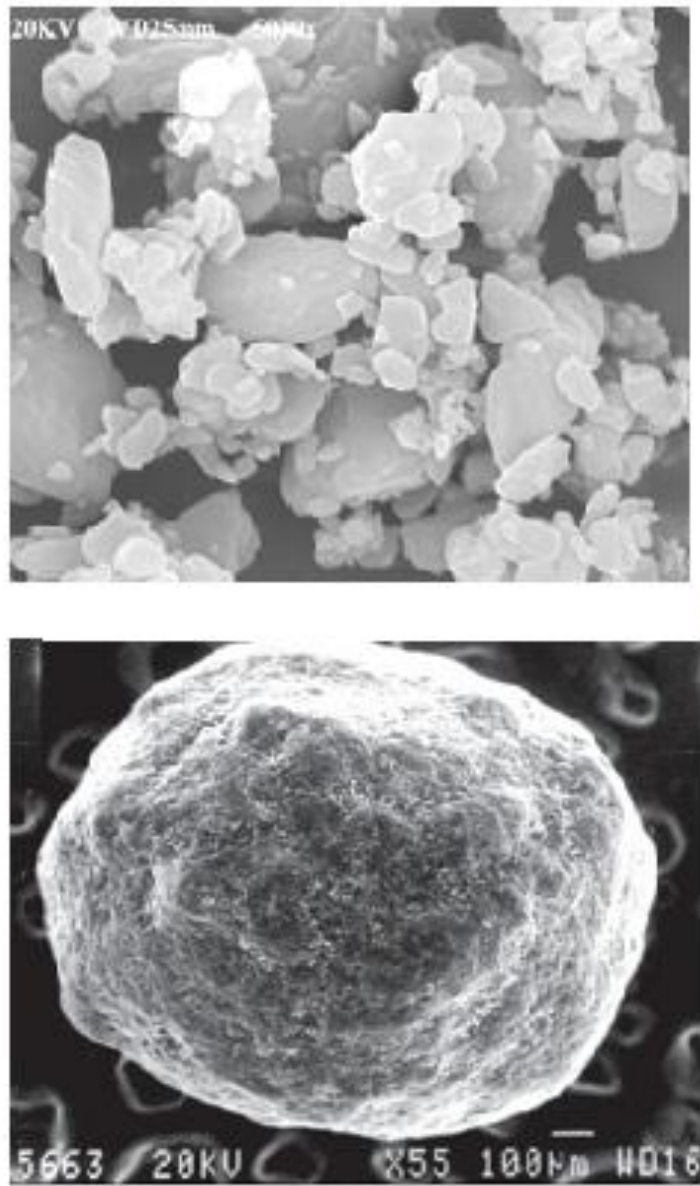

B

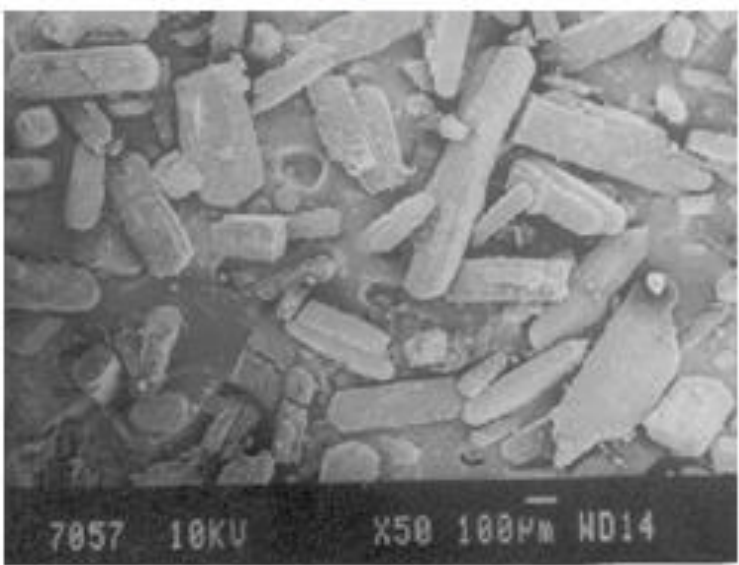

C

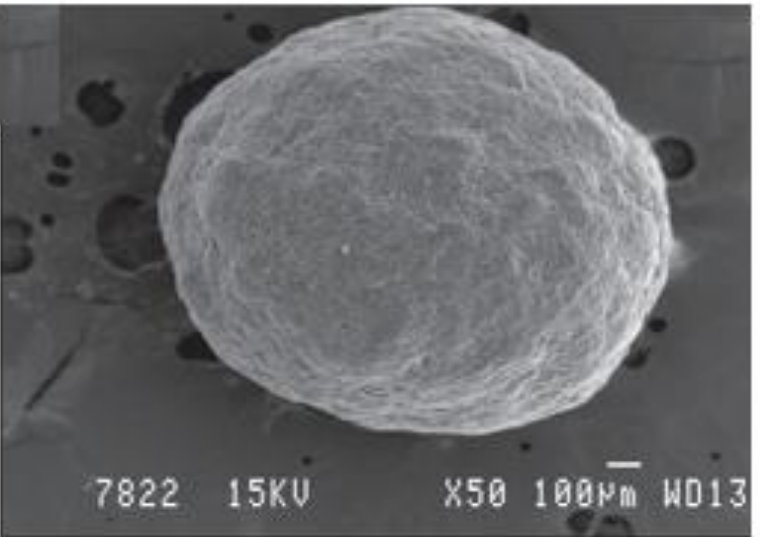

Figure 5. SEM of Naproxen A) pure sample B) Recrystallize in mixture of Iso propyl alcohol: chloroform: water.

C) Spherical agglomerate at $50 \mathrm{X}$ and $55 \mathrm{X}$

groups),1174, 1155, $1223 \mathrm{~cm}^{-1} \quad(-\mathrm{OH}$ group bending vibrations), 1190, $1681 \mathrm{~cm}^{-1}, 1500 \mathrm{~cm}^{-1}-$ $\mathrm{C}=\mathrm{C}$ - of aromatic ring bending vibrations, 1600 $\mathrm{cm}^{-1}$ carboxylate ion. The FTIR spectra of naproxen, recrystallized naproxen and spherical crystals are presented in (Fig. 3).

All the samples showed similar peak positions $(2 \theta)$ in X-ray diffraction, formation of different polymorphs of Naproxen was ruled out. However relative intensities of XRD peaks were modified (Fig. 4). This could be attributed to the markedly different crystal habits of the samples. Therefore the relative abundance of the planes exposed to the X-ray source would have been altered, producing the variations in the relative intensities of the peak or may be due to differences in crystal sizes.
Crystals of pure sample are of the smallest size < $3 \mu \mathrm{m}$ and they have irregular shapes. Recrystallization produced crystals with intermediate size 8-15 $\mu \mathrm{m}$. The agglomerates were formed by coalescence of the microcrystalline precipitates, so the resultant agglomerates had a rough surface (Fig. 5).

The micrometrics properties of pure sample, recrystallized sample and spherical agglomerates of naproxen are shown below in Table 2 . Spherical agglomerates exhibited superior compressibility characteristics compared to conventional drug crystals (Fig. 6).

Dissolution profiles of naproxen crystals showed in Fig. 7. Indicate that the dissolution of naproxen agglomerates was not improved compare to pure sample of naproxen. 


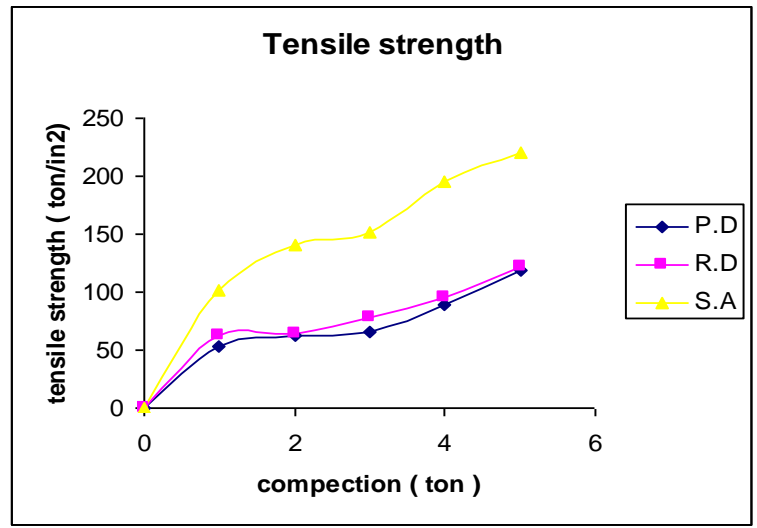

Figure 6. Tensile strength of spherical agglomerates (SA), pure sample (PD) and recrystallized sample (RD) as a function of compaction pressure

The points on the vertex in Ternary diagram (Fig. 1) correspond to a pure liquid; those on the sides correspond to a mixture of only two liquids. Since the presence of three liquids is necessary (good solvent, bridging solvent and poor solvent) for spherical agglomeration, points on the sides of the triangle are excluded. 36 points remain for experiments. Each triangle in the ternary diagram was investigated for the crystallization. The optimal ratio for spherical agglomeration was found in zone shown in Fig. 1. These proportions of tetra-hydro-furan /water/isopropyl acetate (29: 61: 10) were finally chosen for the study.

In DSC study the temperature range of the endothermic peak of all the naproxen crystals were found in the range of $161^{\circ} \mathrm{C}$ to $167^{\circ} \mathrm{C}$. Melting points show slight variation as the nature of the crystals might have been affected by the solvent. The melting endotherm for naproxen agglomerated was $165.72^{\circ} \mathrm{C}$ with decreased enthalpy of $(40.06 \mathrm{~J} / \mathrm{g})$ indicating decreased crystallinity.

Agglomerates obtained were spherical in shape with size $350-830 \mu \mathrm{m}$. The differences in the bulk densities may be related to their markedly different crystal habits, leading to different contact points, frictional and cohesive forces between the crystals spherical agglomerates exhibited higher packing ability than pure sample. It was due to lower surface area and wider particle size distribution of spherical agglomerates. The smaller crystals might have

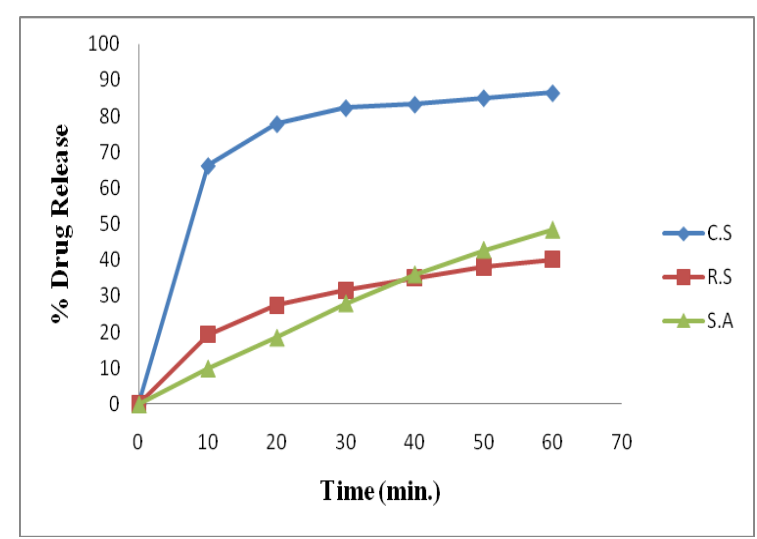

Figure 7. Dissolution profile of Naproxen commercial sample (CS), recrystallized sample (RS) and spherical agglomerates (SA).

settled in voids between larger particles. Three measures of flowability were utilized to analyze the flow of particles. Flow rate measurement allowed quick estimation of flow properties. Angle of repose is able to provide gross measurements of the flowability of crystals. Pure sample exhibited higher angle of repose than spherical agglomerates, due to irregular shape and smaller crystal size. The higher flowability of spherical agglomerates was due to perfect sphericity and larger size of the crystals. The compressibility index is a simple and fast method for estimating flow of powder. Powders with compressibility above $40 \%$ had poor flow. Flow rates were in agreement with morphology and bulk density, spherical agglomerates with low bulk density exhibitd better flow properties.

In tensile strength study, spherical agglomerates exhibited superior compressibility characteristics compared to conventional drug crystals. It could be due to the fact that during the process of compression fresh surfaces were formed by fracturing crystals. Surface freshly prepared by fracture enhanced the plastic inter particle bonding, resulting in a lower compression force required for compressing the agglomerates under plastic deformation compared to that of single crystal.

Dissolution profiles indicate that the dissolution of naproxen is particle size or surface area dependent. Commercial naproxen was available as micronized sample (particle size $<3 \mu \mathrm{m}$ ). Recrystallized naproxen had mean particle size 
of $15 \mu \mathrm{m}$ exhibited $40.17 \%$ dissolution. Spherical crystals prepared by solvent change method had mean particle size of $832.23 \mu \mathrm{m}$ showed higher dissolution $(48.30 \%)$, which may be attributed to increased wetting of particles by bridging liquid. The difference between the packaging arrangements of crystalline forms affected the dissolution of drug. Observations were in agreement with study conducted by Mura et al (1996) on the properties of solid dispersion of naproxen in various polyethylene glycols. Study revealed that the dissolution of naproxen was depressed by the large amount of drug already in the dissolution medium. Study concluded that absence of aggregation and agglomeration of naproxen would increase the dissolution of naproxen. The dissolution behavior of spherical crystals of naproxen was in agreement with findings of Gordon and Chowhan (1990). Gordon and Chowhan modified the crystals of naproxen by the spherical crystallization technique to improve the compression and flow characteristics of the drug using acetone-water system, hexyl alcohol, octyl alcohol, or toluene as bridging liquids. Crystal agglomeration had sufficiently improved the intrinsic compressibility and flow characteristics. However, an increase in drug dissolution could not be achieved by this method.

\section{CONCLUSION}

Spherical crystals of Naproxen were prepared by simple spherical crystallization technique. Spherical crystals exhibited decreased crystallinity and improved micromeritic properties. Amount of bridging liquid, speed of agitation and duration of agitation affects the mechanical and micromeritic properties of spherical crystals. DSC and XRD studies showed that there is no change in the crystal structure of Naproxen during the crystallization process i.e., polymorphism has not occurred. The dissolution of the spherical crystals was not improved compared with pure sample due to the dissolution of naproxen is particle size or surface area dependent. Hence this spherical agglomeration technique is not good method to improve the dissolution rate of Naproxen because of the size of the resulted agglomerates.

\section{ACKNOWLEDGEMENT}

The authors are thankful to Micro labs, Bangalore, India for the gift sample of Naproxan and Principal, J.S.S. College of Pharmacy, Mysore for providing facilities to carry out this work.

\section{REFERENCES}

Chourasia MK, Jain N, Jain SK, Jain S, Jain A and Vaidya S. (2004) Utilisation of spherical crystallization for preparation of directly compressible materials.Indian Drugs. 41(6): 319-329.

Chourasia MK, Jain N, Jain SK, Jain S, Jain NK and Vijaya R. (2004) Preparation and characterization of Spherical crystal agglomerates for direct tabletting by spherical crystallization technique. Indian Drugs. 41(4):214-220.

Gordon, MS and Chowhan, ZT. (1990) Manipulation of naproxen particle morphology via the spherical crystallization technique to achieve a directly compressible raw material. Drug Dev. Ind. Pharm. 16(8): 1279-1290.

Janos B, Geza RJ, Klara PH, Ljiljana T, Odon P and Zsofia T. (2004) StaneSrcic, Istavan Eros. Surface treatment of indomethacin agglomerates with eudragit. Drug Dev Ind Pharm. 30(4):381-388.

Kulkarni PK and Nagav BGi. Spherical crystallization: (2002) Indian J Pharm Edu; 36:66-73.

Martino DP, Barthelemy C, Joiris E, Martelli S and Palmieri GF. (1999) Improved dissolution behaviour of Fenbufen by spherical crystallization. Drug DevInd Pharm. 25(10): 1073-1081.

Mura PA. Ceccarelli L and Manderioli GB. (1996) Properties of solid dispersion of naproxen in various polyethylene glycols Drug Dev. Ind. Pharm. 22(9\&10): 909-916.

Nocent M, Bertocchi L, Baron M, Courraze G and Espitalier F. (2004) Definition of a solvent system for spherical crystallization of salbutamol sulfate by quasi-emulsion diffusion (QESD) method. J Pharm Sci. 90(10):1620-1627.

Paradkar AR, Chordiya JK, Ketkar AR Pawar AP and Patil VB. (2002) Spherical crystallization of celecoxib. Drug Dev Ind Pharm; 28(10):1213-1220.

Piera DM, Christine B, Etienne J, Giovanni PF, Martelli S and Roberta DC. (2000) Improved compression properties of propyphenazone spherical crystals. Int J Pharm. 197(1-2):95-106.

Sano A, Handa T, Kuriki T, , Kawashima Y and Takeuchi H. (1987) Particle design of tolbutamide in the presence of soluble polymer or surfactant by the 
spherical crystallization technique: improvement of dissolution rate. J Pharm Sci. 76(Jun): 471-474.

Sano A, Hino T, Kuriki T, Kawashima Y, Niwa T and Takeuchi H. (1990) Particle design of tolbutamide by spherical crystallization technique. V. Improvement dissolution and bio availability of direct compressed tablets prepared using tolbutamide agglomerated crystals. Chem Pharm Bull. 40(11):3030-3035.

Takeo K, Hirofumi T, Kawashima.Y, Tomoaki H and Toshiyuki N. (1990) Modification of tolbutamide by solvent change technique. III. Micromeritic properties, dissolution rate of tolbutamide spherical agglomerates prepared by QESD method and SC method.Chem Pharm Bull. 38(3):733-739.

Yousef J, Mohammad R, Mohammad BJ and Siahi S. (2005) The effect of type and concentration of vehicles on the dissolution rate of a poorly soluble drug (indomethacin) from liquisolid compacts. J Pharm Sci; 8(1):18-25. 